\title{
Photocatalytic degradation of Rose Bengal dye over mechanochemically synthesized zinc oxide under visible light irradiation
}

\author{
Y. D. Kaldante ${ }^{1,3}$, R. N. Shirsat ${ }^{3}$, M. G. Chaskar ${ }^{1,2}$ \\ ${ }^{1}$ Department of Chemistry, PDEA's Baburaoji Gholap College, Sangvi, Pune, Maharashtra - 411027, India \\ ${ }^{2}$ Department of Chemistry, PDEA's Prof. Ramkrishna More College, Akurdi, Maharashtra - 411044, India \\ ${ }^{3}$ Department of Chemistry, PDEA's Annasaheb Waghire College, Otur, Tal. Junnar, Dist. Pune, Maharashtra - \\ 412409, India \\ ydkaldante@gmail.com,manohar_c@hotmail.com
}

DOI 10.17586/2220-8054-2021-12-6-773-782

\begin{abstract}
Present work summarized efficient synthesis of $\mathrm{ZnO}$ by mechanochemical method via zinc oxalate dihydrate precursor for studies of the photocatalytic degradation of Rose Bengal dye. The process of conversion of zinc oxalate dihydrate to ZnO was studied by TGA-DTG analysis and FT-IR Spectroscopy, XRD data obtained clearly revealed the hexagonal wurtzite crystallite structures of ZnO. FE-SEM images confirmed nanocrystalline morphology of $\mathrm{ZnO}$ with an approximately uniform particle size distribution. The purity of ZnO was confirmed by EDX study. The optical band gap of ZnO was determined from UV-Visible spectroscopy. The photocatalytic activity of ZnO was investigated with degradation of Rose Bengal dye. The colorimetric absorbance measurement was used to estimate degradation efficiency. The catalytic activity was studied with reference to the condition of dye concentration, photocatalyst loading capacity, $\mathrm{pH}$ of dye solution, irradiation time, etc. Photocatalytic degradation of Rose Bengal dye over mechanochemically synthesized $\mathrm{ZnO}$ under visible light irradiation was successfully studied.
\end{abstract}

Keywords: zinc oxide, Rose Bengal, degradation efficiency, photocatalysis.

Received: 7 August 2021

Revised: 30 October 2021

\section{Introduction}

Water scarcity is one of the most serious problems presently we are facing all over the world. Prolonged shortages in the water supply have a substantial impact not only on the ecosystem and agriculture [1] but also harm local economies [2]. Consequently, water shortages create environmental, economic and social problems. The lack of water for prolong period of time results in a drought. Some common consequences of drought includes reduced crop growth or yield productions [1], soil erosion, desertification [3] and dust storms [4], habitat damage, affecting both terrestrial [5] and aquatic wildlife [6], hunger, malnutrition, dehydration and related diseases, mass migration [7], reduced hydroelectric power production, shortages of water for industrial uses [4], social unrest [8], wildfires [3], accumulation of cyanotoxin within food chains and water supply can cause cancer with low exposure over the long term [9]. Increased demands of clean intake water and water for sterilization are the major present problems of our society [10]. To deal with the problems of water scarcity, drought situations as well as to fulfill the demands of society, water treatment or detoxification and rain water harvesting are the best initiatives which need to be executed.

The process of removal of undesirable chemicals, biological contaminants, suspended solids and gases from water is called as water purification. It is necessary to produce pure water suitable for specific purposes such as drinking, pharmacological, medical, chemical and industrial applications. The clarification or purification of water can be achieved by physical methods like filtration, distillation and sedimentation; biological methods like slow sand filtration, biologically activated carbon filtration; chemical methods such as chlorination, flocculation and the use of ultraviolet light. All these are the conventional methods of water treatment and purification which are not always suitable for treating moderate to high concentration waste waters.

The execution of solar light driven advanced oxidation processes (AOPs) has been an auspicious alternative for the detoxification of industrial effluents [11-14], and thus, for environmental protection [14]. The coloring agent dyes are the organic substances mainly used in textile, paper, printing, leather and plastics industries are most common and are one of the major contaminant responsible for water pollution. The photocatalysis is one of the most efficient and economical method among AOPs employed for the total mineralization of organic contaminants to $\mathrm{CO}_{2}, \mathrm{H}_{2} \mathrm{O}$ and inorganic salts [15-18]. Metal oxides like $\mathrm{TiO}_{2}, \mathrm{ZnO}, \mathrm{SnO}_{2}, \mathrm{NiO}, \mathrm{Cu}_{2} \mathrm{O}, \mathrm{Fe}_{3} \mathrm{O}_{4}$, etc. have been effectively utilized as a heterogeneous photocatalyst for dye degradation. These are nontoxic, stable, highly photosensitive, wide band gap materials. An activated semiconductor metal oxide usually promotes the photodegradation of dyes under solar light [19]. In this method, a semiconductor metal oxide catalyst is illuminated with solar light or a suitable light source, electron-hole pairs are generated in the oxide material. Due to intensive reduction potential of the holes 
present in the valence band, it gives in situ generation of hydroxyl radicals. Due to the high redox potential (2.8 V) of hydroxyl radicals, they are capable of complete non-selective breakdown of the dye molecules [20]. Among the various metal oxides, $\mathrm{ZnO}$ was found to be the most suitable candidate for the visible light mediated photocatalysis, so, for the present study, $\mathrm{ZnO}$ was selected. Also, due to its simple, economic and environmentally friendly nature, the mechanochemical method was selected for the present study.

One of the extensively used classes of dyes is xanthene dyes containing xanthene nucleus with aromatic groups as the chromophore. These dyes are widely used as colorants in the textile, printing and dyeing industries. These dyes are reported to be genotoxic, mutagenic, cytotoxic and cytostatic [21-25]. Rose Bengal is one of the widely used anionic water-soluble and important xanthene dyes in textile, dyeing and photochemical industries. Therefore, for the present study, Rose Bengal is taken as a model dye for the photocatalytic degradation over ZnO photocatalyst. The chemical structure of the dye molecule is shown in Fig. 1.
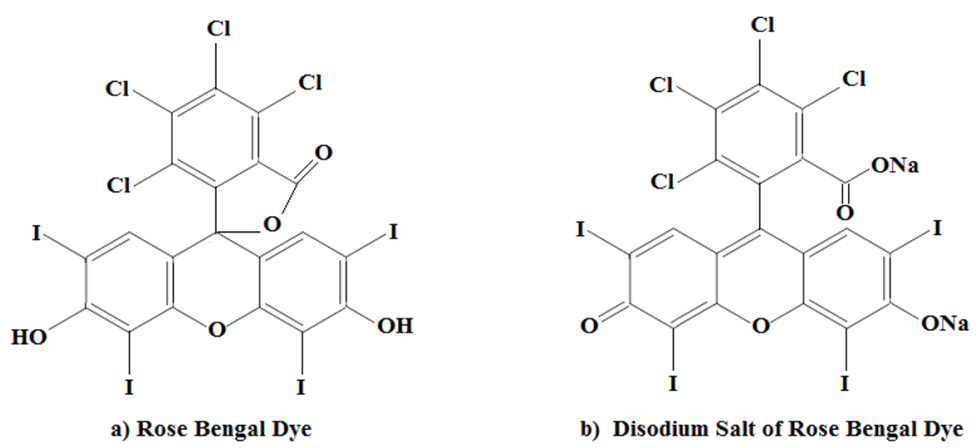

FIG. 1. Chemical structure of the Rose Bengal dye molecule

In this study, an attempt was made to synthesize the $\mathrm{ZnO}$ by efficient, solution free mechanochemical method and study the photocatalytic degradation of Rose Bengal dye over this $\mathrm{ZnO}$ in presence of artificial light (visible). The various operational parameters such as dye concentration, photocatalyst loading capacity, $\mathrm{pH}$ of dye solution, irradiation time, etc. were studied in detail. Further exploration of this work is particularly beneficial for the water treatment by photocatalysts in those areas of the world where solar light is not abundantly available.

\section{Experimental}

\subsection{Materials}

Zinc acetate dihydrate (assay $99.5 \%$ ), oxalic acid dihydrate (assay 99.0\%), Rose Bengal disodium salt (assay $99.5 \%$ ) and other essential chemicals used during this work were AR grade reagents obtained from S. D. Fine Chemicals, India and used without further purification. All the experimental solutions were prepared in distilled water. The $\mathrm{pH}$ of these solutions was adjusted to the desired values with aqueous $\mathrm{NaOH}(0.1 \mathrm{~N})$ and $\mathrm{H}_{2} \mathrm{SO}_{4}(0.1 \mathrm{~N})$ wherever necessary.

\subsection{Synthesis of photocatalyst}

Powdered zinc oxide $(\mathrm{ZnO})$ catalyst was prepared by a two-step method. In the first step zinc oxalate dihydrate precursor was obtained simply by mechanical hand grinding of a mixture of $10.975 \mathrm{~g}$ of zinc acetate dihydrate with $6.93 \mathrm{~g}$ of oxalic acid dihydrate in an agate mortar for $20-30$ minutes at room temperature. In second step the zinc oxalate dihydrate precursor was subjected to thermal disintegration by calcination at $450{ }^{\circ} \mathrm{C}$ leads to the formation of $\mathrm{ZnO}[26]$.

$$
\begin{aligned}
\mathrm{Zn}\left(\mathrm{CH}_{3} \mathrm{COO}\right)_{2} \cdot 2 \mathrm{H}_{2} \mathrm{O}+\mathrm{H}_{2} \mathrm{C}_{2} \mathrm{O}_{4} \cdot 2 \mathrm{H}_{2} \mathrm{O} & \longrightarrow \mathrm{ZnC}_{2} \mathrm{O}_{4} \cdot 2 \mathrm{H}_{2} \mathrm{O}+2 \mathrm{CH}_{3} \mathrm{COOH}+2 \mathrm{H}_{2} \mathrm{O} \\
\mathrm{ZnC}_{2} \mathrm{O}_{4} \cdot 2 \mathrm{H}_{2} \mathrm{O} & \longrightarrow \mathrm{ZnO}+\mathrm{CO}_{2}+\mathrm{CO}+2 \mathrm{H}_{2} \mathrm{O} .
\end{aligned}
$$

\subsection{Equipment}

The temperature of the transformation of zinc oxalate dihydrate precursor to the zinc oxide was obtained by thermogravimetric analysis machine (Shimadzu, TG-DTG-60H) and FT-IR (PerkinElmer UATR Spectra Two) spectrometer. For $\mathrm{ZnO}$ crystallite, the X-ray diffraction (XRD) pattern was obtained with X-ray Diffractometer (Rikagu 
Miniflex-600) using $\mathrm{CuK} \alpha$ radiation $(\lambda \alpha=1.5418 \AA$ ) and the average crystallite size $(D)$ of the particles was determine from the Debye-Scherer equation [27]: $D=\frac{0.90 \times \lambda}{\beta \times \cos \theta}$ where, $\lambda$ is the wavelength $(\mathrm{CuK} \alpha), \beta$ is the full width at the half maximum (FWHM) of the most intense peak (101) in the XRD pattern of $\mathrm{ZnO}$ and $\theta$ is the diffraction angle [27]. The morphological characterization of powder was performed by using FE-SEM (JEOL JSM-6360A). The elemental composition of the $\mathrm{ZnO}$ was studied with energy dispersive $\mathrm{X}$-ray (EDX) spectra. The optical band gap of $\mathrm{ZnO}$ was estimated from UV-Visible spectra obtained with UV-Visible Spectrophotometer (PerkinElmer Lambda 365). The photocatalytic reactions were carried out at room temperature in batch reactor under adequately constant intensity visible light irradiation source (400W MH-TBT-E40) providing nearly $0.4-0.6 \mathrm{~kW} / \mathrm{m}^{2}$ radiation intensity at $15 \mathrm{~cm}$ distance. Colorimetric absorbance measurement with digital colorimeter (EQUIP-TRONICS EQ-353) was utilized to determine the degradation efficiency. The preliminary $\mathrm{pH}$ of suspension was adjusted with the help of $\mathrm{pH}$ meter (LABTRONICS LT-11). A Lux meter HTC LX-100 was used to measure the light intensity.

\subsection{Photocatalytic degradation experiments}

For optimization of photocatalytic parameters and photocatalytic degradation studies, Rose Bengal dye solutions with variable initial concentration were prepared using double distilled water. All experiments are conducted in a batch photoreactor with glass cool trap and magnetic stirrer. Rose Bengal $(100 \mathrm{~mL})$ dye solution having known preliminary concentration at suitable $\mathrm{pH}$ and at room temperature was taken with known extent of zinc oxide powder in a photoreactor with $5 \mathrm{~cm}$ diameter. Mixture was then subjected to ultrasonic agitation for 5 minutes to obtain a uniform suspension. Container was then fixed on magnetic stirrer kept under adequately constant intensity visible light irradiation source (400W MH-TBT-E40) at a distance of $15 \mathrm{~cm}$. At specified time intervals supernatant solution $(5.0 \mathrm{ml})$ was collected and centrifuged to settle down $\mathrm{ZnO}$ particles. Then absorbance was recorded at predetermined $\lambda_{\max }(500 \mathrm{~nm})$ value of Rose Bengal dye solution using a digital colorimeter. The degradation efficiency was estimated from the colorimetric absorbance measurement as percent (\%) Degradation: $\% D=\frac{100 \times\left[A_{0}-A_{t}\right]}{\left[A_{0}\right]}$, where $\% D-$ percent degradation, $A_{0}$ - initial absorbance, $A_{t}$ - absorbance at time $t$.

\section{Result and discussion}

\subsection{Characterization of zinc oxide}

The process of conversion of zinc oxalate dihydrate to Zinc Oxide $(\mathrm{ZnO})$ was studied by TGA-DTG analysis and FT-IR Spectroscopy. The ZnO thus obtained was further characterized by X-ray diffraction, FE-SEM and EDX study. The optical band gap of $\mathrm{ZnO}$ was determined from UV-Visible spectroscopy.

3.1.1. Thermal gravimetric analysis. Fig. 2 shows the TGA-DTG plots for zinc oxalate dihydrate precursor. From the DTG plot it is clear that, the thermal disintegration of zinc oxalate dihydrate precursor occurred with three endothermal steps from 30 to $450{ }^{\circ} \mathrm{C}$ to give $\mathrm{ZnO}$. The $1.40 \%$ weight loss from 30 to $105{ }^{\circ} \mathrm{C}$ is due to the removal of residual acetic acid. The $17.71 \%$ weight loss from 105 to $165^{\circ} \mathrm{C}$ is due to removal of adsorbed water, residual water and residual acetic acid (Boiling Point $118{ }^{\circ} \mathrm{C}$ ). The $37.35 \%$ weight loss from 335 to $455{ }^{\circ} \mathrm{C}$ in $\mathrm{TG}$ curve is recognized to the decomposition of oxalate moiety from zinc oxalate. From this, the conversion temperature for zinc oxalate dihydrate to zinc oxide is $455^{\circ} \mathrm{C}$.

3.1.2. FT-IR spectroscopic study. Fig. 3 shows changes in the FT-IR spectra during the transformation of zinc acetate dihydrate to zinc oxide through zinc oxalate precursor. The replacement of acetate ions in the zinc acetate dihydrate by oxalate ions to yield zinc oxalate precursor during mechanical grinding with oxalic acid is clearly understood with the help of diminishing of bands corresponding to various symmetric and asymmetric stretching and bending vibrations in the acetate group $\left(621,686,952,1016,1426,1542,1664,3073 \mathrm{~cm}^{-1}\right)$ and enhancement of the bands corresponding to various symmetric and asymmetric stretching and bending vibrations in the oxalate group $(547,720,1116,1608$, $\left.3412 \mathrm{~cm}^{-1}\right)$. Zinc oxalate precursor shows well defined bands $(493,588,723,822,1122,1245,1319,1364,1626$, 1888 and $3390 \mathrm{~cm}^{-1}$ ). Diminishing of all bands other than that centered at $450 \mathrm{~cm}^{-1}$ upon calcination of zinc oxalate precursor at $500{ }^{\circ} \mathrm{C}$ confirms the formation of spherical shape $\mathrm{ZnO}$ and same also confirmed by XRD study.

3.1.3. X-Ray diffraction (XRD) study. The XRD peak position and intensity data for synthesized $\mathrm{ZnO}$ was procured over the appropriate $\left(20-80^{\circ}\right) 2 \theta$ range with $\mathrm{CuK} \alpha$ radiation $(\lambda=1.5418 \AA$ ). The data contained (Fig. 4) a series of peaks centered at $2 \theta=31.74,34.38,36.22,47.50,56.58,62.82,66.36,67.90,69.08,72.62,76.86^{\circ}$ belonging to the (100), (002), (101), (102), (110), (103), (200), (112), (201), (004) and (202) planes respectively, which are in very fine agreement with the JCPDS card for the standard hexagonal wurtzite structure of pure $\mathrm{ZnO}[26,28]$. 


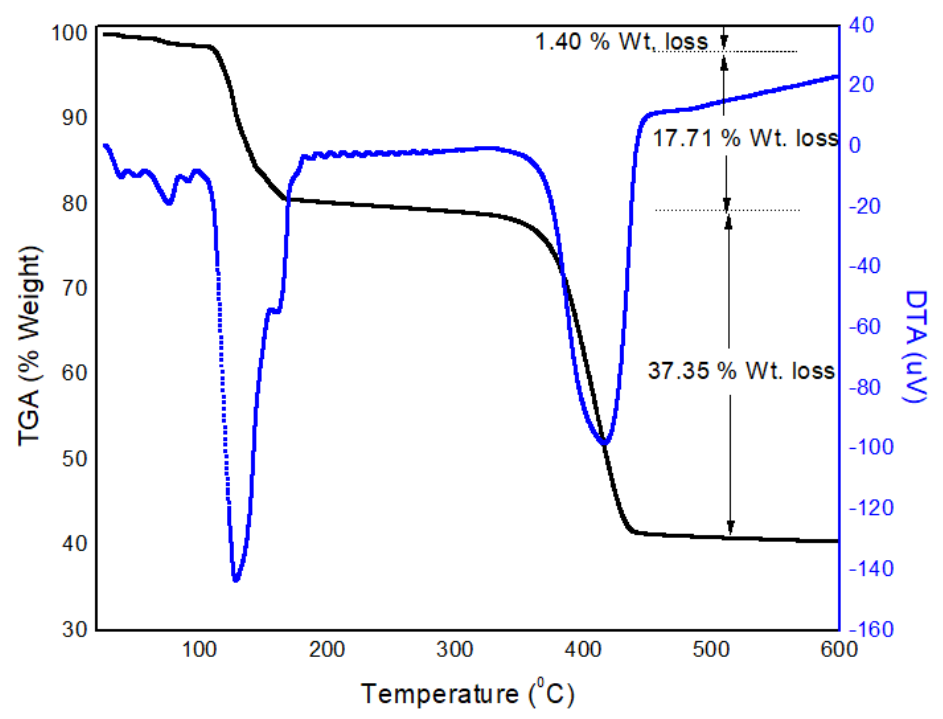

FIG. 2. TG-DTA plots for Zinc Oxalates Dihydrate

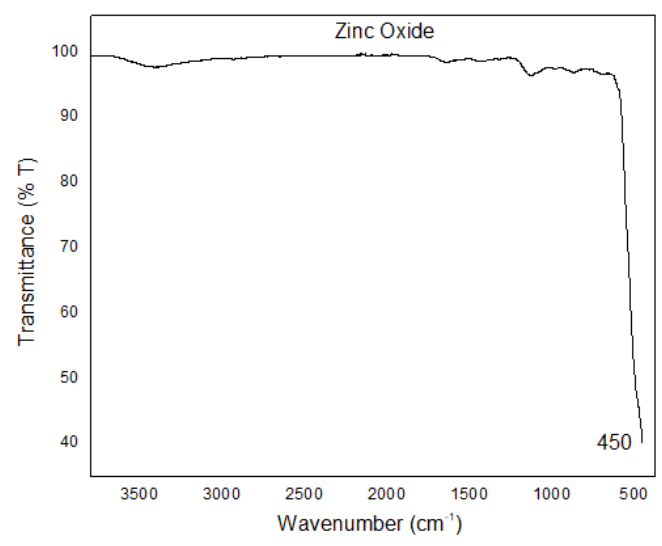

(a)

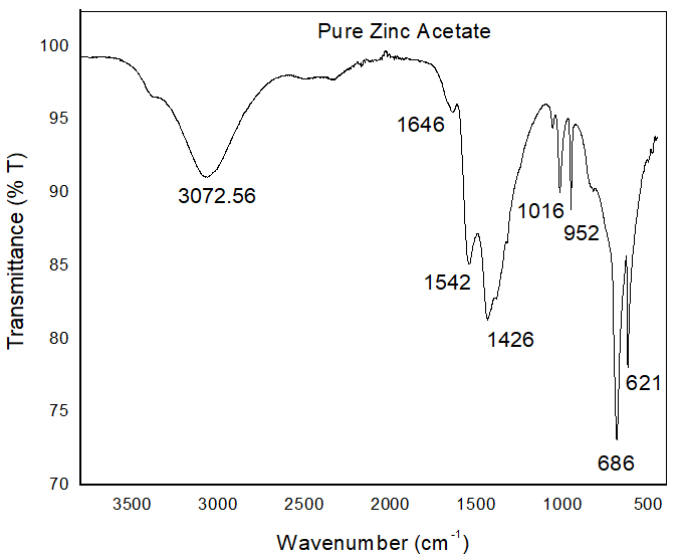

(c)

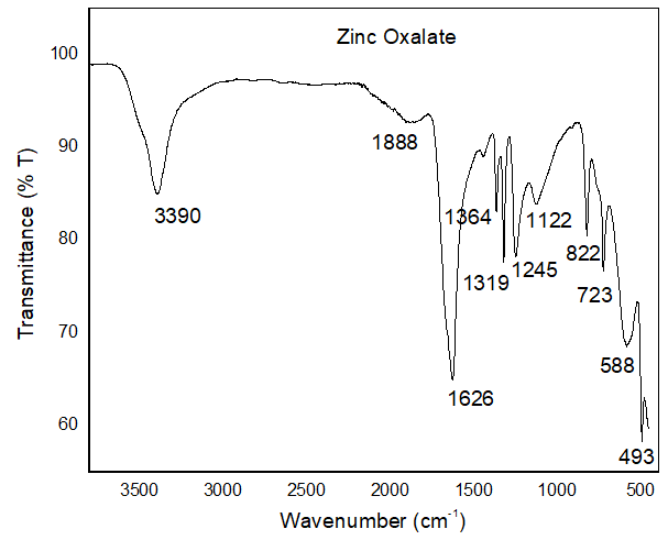

(b)

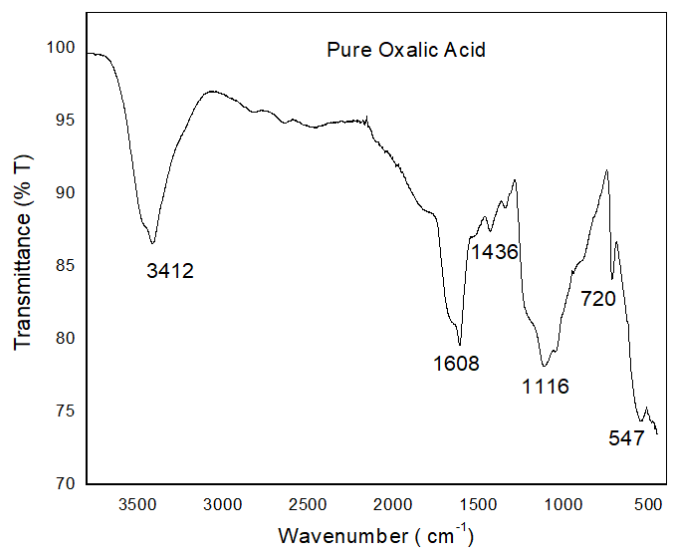

(d)

FIG. 3. Changes in FT-IR spectra during the transformation of $\mathrm{ZnC}_{2} \mathrm{O}_{4} \cdot 2 \mathrm{H}_{2} \mathrm{O}$ to $\mathrm{ZnO}$ 


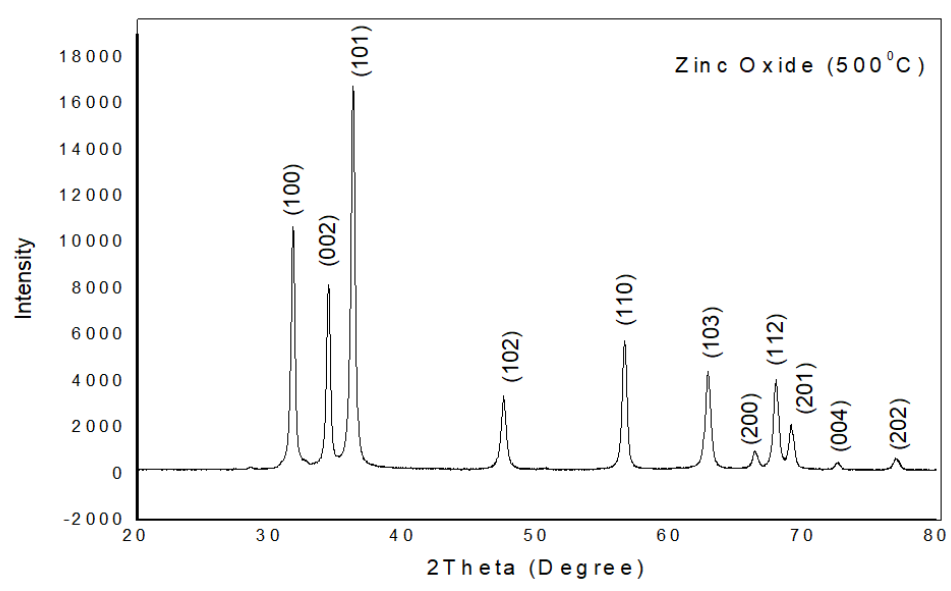

FIG. 4. XRD pattern of Zinc Oxide

The mean crystallite size of $\mathrm{ZnO}$ was calculated from data of most intense peak corresponding (101) crystal plane using Debye Scherer's formula [27] and was found to be $18.67 \mathrm{~nm}$, corresponding to the mean FWHM $=0.4237$ also the lattice strain calculated by using tangent formula [29] was found to be 0.324 . Also, the specific surface area was determined by using Sauter Formula [30] and was found to be $57.33 \mathrm{~m}^{2} / \mathrm{g}$.

3.1.4. FE-SEM study. The morphological characterization of $\mathrm{ZnO}$ was studied by using field emission scanning electron microscopy (FESEM). Fig. 5 indicates the FESEM image ZnO powder. Formation of nearly homogeneous phase having non-agglomerated, dense particles of hexagonal morphology is clearly seen from the FE-SEM image. Nearly uniform particle size distribution is also found. The mean particle size is found be around $31.62 \mathrm{~nm}$.

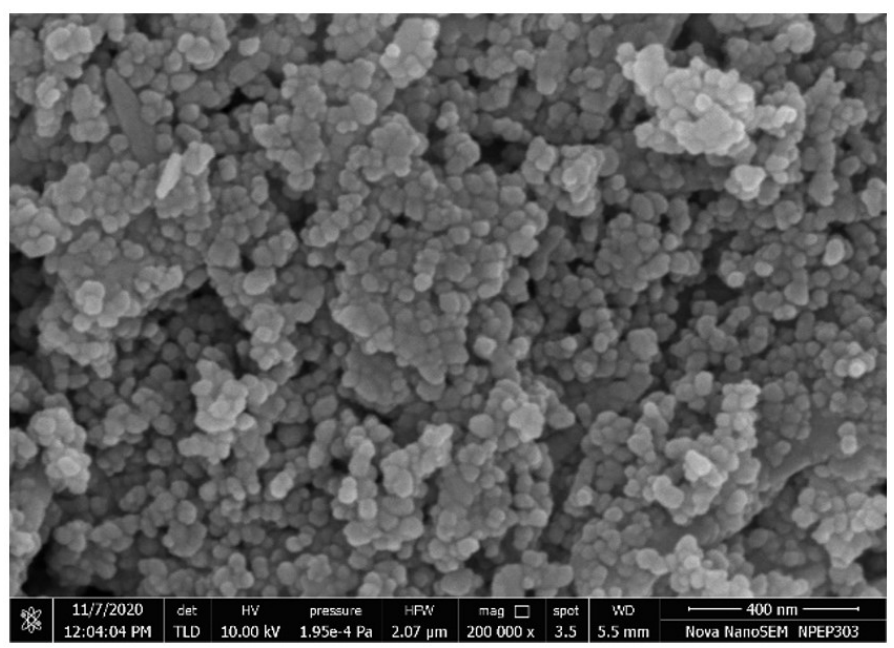

FIG. 5. FE-SEM image of Zinc Oxide

3.1.5. EDX analysis. Energy Dispersive X-ray (EDX) spectra of $\mathrm{ZnO}$ is shown in Fig. 6(a), which shows peaks corresponding to $\mathrm{Zn}$ and $\mathrm{O}$ only in significance with purity of the zinc oxide. Also elemental mapping showing distribution of $\mathrm{Zn}$ and $\mathrm{O}$ is shown in the Fig. 6(b).

3.1.6. UV-Visible spectra. Fig. 7 represents UV-visible Spectra of $\mathrm{ZnO}$ which shows evidently situated optical extinction bands in the range of 370 to $415 \mathrm{~nm}$. The calculated band gap energy of $\mathrm{ZnO}$ was found to be $3.14 \mathrm{eV}$. 


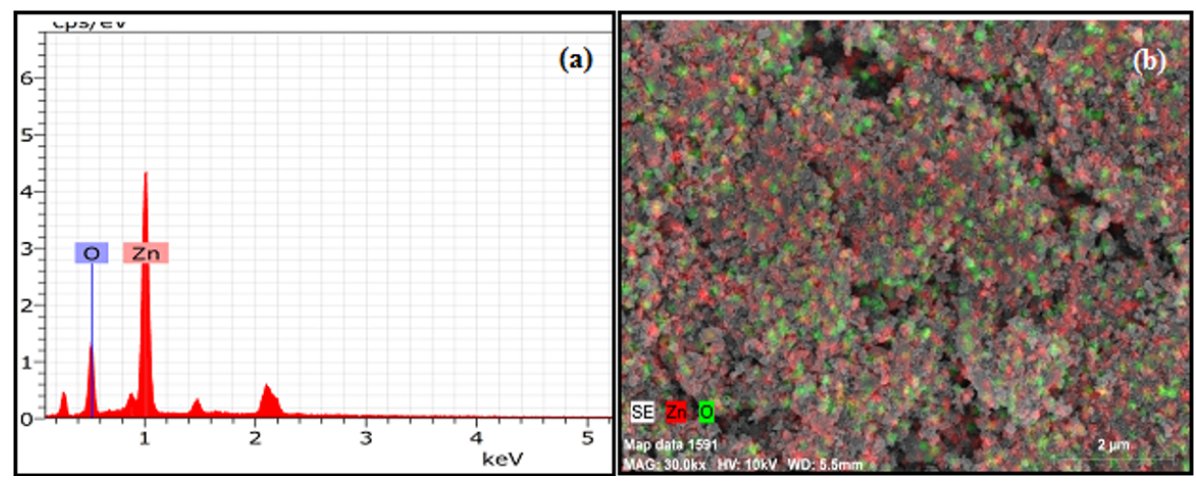

FIG. 6. Zinc Oxide's EDX Spectra Figure (a) and Elemental Mapping Figure (b)

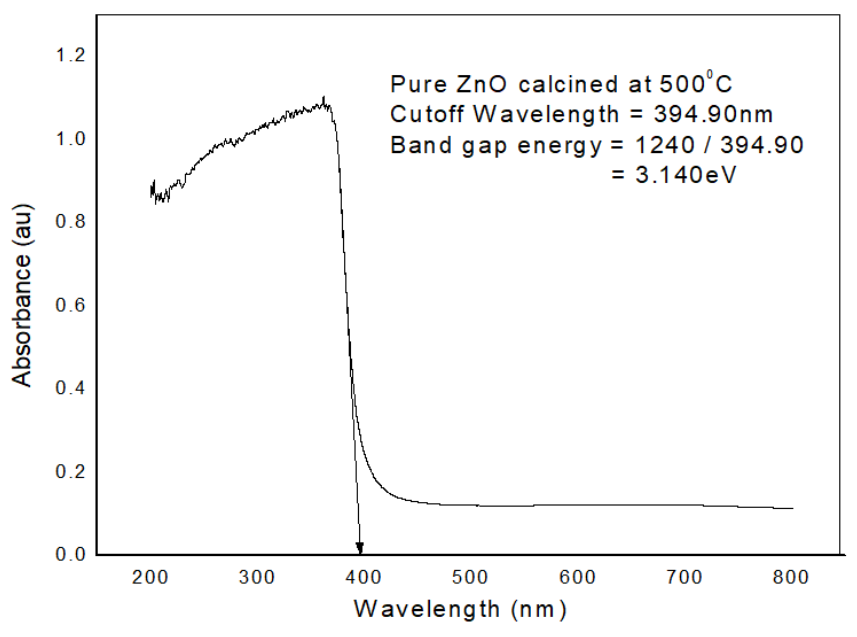

FIG. 7. UV-visible Spectra of $\mathrm{ZnO}$

\subsection{Optimization of photocatalytic operational parameters for degradation of Rose Bengal over ZnO catalyst}

3.2.1. Mechanism of Rose Bengal dye degradation. An advanced oxidation process is involved in the photocatalytic degradation of Rose Bengal dye [19]. Upon absorption of photons by photosensitive Rose Bengal dye, the molecule forms an excited singlet state $\left(\mathrm{RB}_{1}\right)$, which is then converted to excited triplet state $\left(\mathrm{RB}_{2}\right)$ by means of inter system crossing (ISC). Zinc oxide ( $\mathrm{ZnO}$ ), upon irradiation, excites the electron from valence band to conduction band and a hole left behind on the valence band. This hole adsorbs an electron from water or hydroxide ion to produce $\cdot \mathrm{OH}$ radical. The radicals oxidize the Rose Bengal dye to its colorless leuco form and finally to harmless compounds [19].

The most feasible mechanism is as follows [19]:

$$
\begin{aligned}
& \mathrm{RB}_{0}+h \nu \longrightarrow \mathrm{RB}_{1}, \\
& \mathrm{RB}_{1} \stackrel{(I S C)}{\longrightarrow} \mathrm{RB}_{2}, \\
& \mathrm{ZnO}+h \nu \longrightarrow h^{+}(\mathrm{VB})+e^{-}(\mathrm{CB}) \\
& \mathrm{H}_{2} \mathrm{O}+h^{+} \longrightarrow \cdot \mathrm{OH}+\mathrm{H}^{+}, \\
& \mathrm{O}_{2}+e^{-} \longrightarrow \cdot \mathrm{O}_{2^{-}}, \\
& \cdot \mathrm{O}_{2^{-}}+\mathrm{H}^{+} \longrightarrow \cdot \mathrm{HO}_{2^{-}}, \\
& \mathrm{RB}_{2}+\cdot \mathrm{OH} \longrightarrow \text { Leuco } \mathrm{RB}, \\
& \text { Leuco } \mathrm{RB} \longrightarrow \text { Products. }
\end{aligned}
$$


Optimization of the photocatalytic degradation of Rose Bengal over $\mathrm{ZnO}$ surface was explored by varying the operational parameters, e.g.: the initial $\mathrm{pH}$ of the suspension $(6-10)$, $\mathrm{ZnO}$ loading quantity $(50-150 \mathrm{mg} / 100 \mathrm{ml})$, initial dye concentration $(50-150 \mathrm{ppm})$, illumination time ( $0-6$ hours) under adequately constant intensity visible light irradiation source. The degradation efficiency was estimated from the colorimetric absorbance measurement as percent (\%) Degradation: $\% D=\frac{100 \times\left[A_{0}-A_{t}\right]}{\left[A_{0}\right]}$, where $\% D$ - percent degradation, $A_{0}$ - initial absorbance, $A_{t}-$ absorbance at time $t$. The results encountered are detailed as follows.

3.2.2. Effect of the initial $\mathrm{pH}$ of Rose Bengal dye solution. The effect of initial $\mathrm{pH}$ of the Rose Bengal dye solution over the $\mathrm{pH}$ range $6-10$ was studied with arbitrary chosen $50 \mathrm{ppm}$ dye solution and $100 \mathrm{mg} \mathrm{ZnO/} 100 \mathrm{ml}$ loading with 4 hours of irradiation time. The $\mathrm{pH}$ of the dye solutions was adjusted only at initial stage and not controlled during the course of reaction. The other parameters were kept constant. The results gained are indicated in Fig. 8. The slight solubility of $\mathrm{ZnO}$ in acidic medium (pH 6) may be reflected in the decreased degradation of Rose Bengal in acidic medium [31]. Also up to $\mathrm{pH} 6$ to 8 the dye molecule remains in its protonated form and also $\mathrm{ZnO}$ catalyst is somewhat positively charged due to adsorption of protons, hence, the dye molecules and $\mathrm{ZnO}$ repel each other. which results in a low degradation efficiency. The percent degradation was found to be maximum (100\%) at pH 8, where the repulsion between dye molecule and $\mathrm{ZnO}$ catalyst is at its lowest. Beyond $\mathrm{pH} 8$, the rate of degradation decreases with increase in initial $\mathrm{pH}$ from 9 to 10 , this is due to negative charge produce on the $\mathrm{ZnO}$ due to adsorption of hydroxyl ions and hence anionic dye molecule again face intermolecular repulsion [19]. The $\mathrm{pH}$ value of 8 is thus optimum for the photocatalytic degradation of Rose Bengal dye.

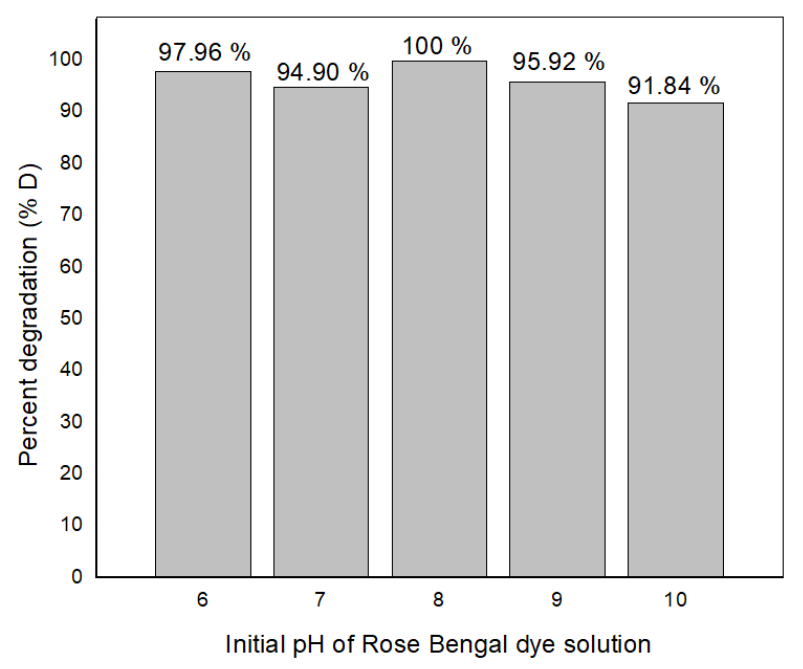

FIG. 8. Variation of percent (\%) degradation of Rose Bengal dye with initial $\mathrm{pH}$ of dye solution

3.2.3. Effect of the photocatalyst $(\mathrm{ZnO})$ quantity. The blank experiments were carried out in absence of $\mathrm{ZnO}$ to know the extent to which Rose Bengal dye photolyzed. In absence of $\mathrm{ZnO}$, Rose Bengal dye photolyzed to the extent of only $20-23 \%$. When aqueous solution of Rose Bengal dye containing ZnO was irradiated with light PCD of Rose Bengal was observed to a greater extent. The amount of catalyst used for dye degradation has a profound impact on the rate of degradation [32]. The optimum amount of $\mathrm{ZnO}$ required for thorough mineralization of $100 \mathrm{ml}, 50 \mathrm{ppm}$ Rose Bengal dye at an optimum $\mathrm{pH} 8$ to $\mathrm{CO}_{2}$ and $\mathrm{H}_{2} \mathrm{O}$ and inorganic ions was inspected by changing the amount of $\mathrm{ZnO}$ from 25 to $150 \mathrm{mg} / 100 \mathrm{ml}$ and upon 3.5 hours of irradiation. From the Fig. 9, it is depicted that the percent of dye degraded increases with an increased amount of $\mathrm{ZnO}$ loading from 25 to $150 \mathrm{mg} / 100 \mathrm{ml}$. As the amount of $\mathrm{ZnO}$ increases, the surface area of catalyst increases, hence adsorption of dye molecules over the surface of $\mathrm{ZnO}$ increases, which increases the percent degradation. Also, increasing amount of photocatalyst increases the number of active sites on its surface, which promotes an increased number of photogenerated electron-hole pair, hence the number of hydroxyl radicals responsible for dye degradation.

From the above data, one can see $100 \%$ dye degradation is observed for in each case of catalytic loading $125 \mathrm{mg}$ $\mathrm{ZnO} / 100 \mathrm{ml}$ dye solution and $150 \mathrm{mg} \mathrm{ZnO/} 100 \mathrm{ml}$ dye solution. The $100 \mathrm{mg} \mathrm{ZnO/} 100 \mathrm{ml}$ dye solution is selected as optimum catalyst loading for the present study; doing so circumvents the formation of a turbid solution and thus avoids the shadowing and screening effect for the light photons due to scattering of light, which negatively impacts photodegradation $[33,34]$. 


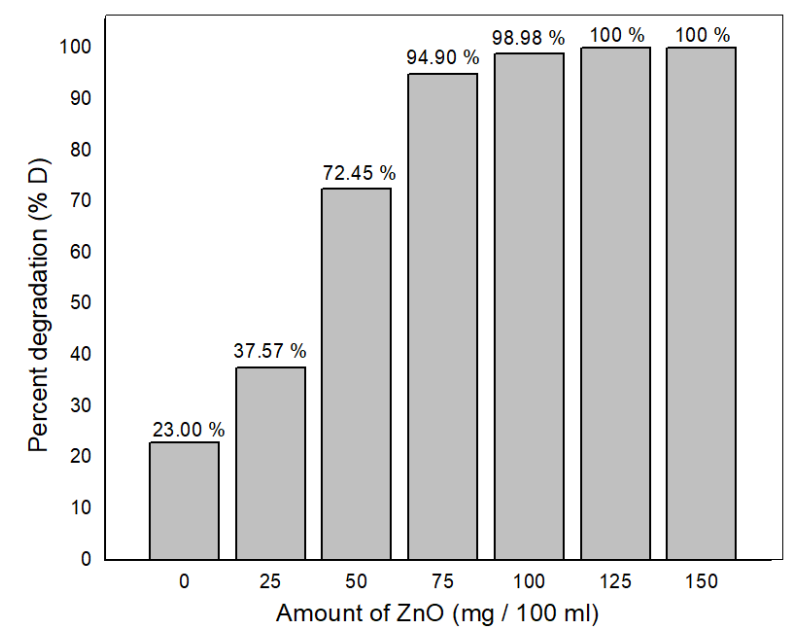

FIG. 9. Variation of percent (\%) degradation of Rose Bengal dye with catalyst (ZnO) quantity

3.2.4. Effect of the initial concentration of Rose Bengal dye solution. The degradation of Rose Bengal dye was studied at different initial concentrations ranging from 25 to $150 \mathrm{ppm}$ with respect to 4 hours of illumination time under the optimum conditions (Catalytic loading $100 \mathrm{mg} \mathrm{ZnO/} 100 \mathrm{ml}$ of dye solution at $\mathrm{pH}$ 8). The results gained are indicated in Fig. 10. As expected the increased initial concentration of the dye solution has a negative impact on percent degradation due to the fact that, under constant conditions of catalytic amount and irradiation time the same number of reactive radicals were generated on the surface of $\mathrm{ZnO}$, but more and more dye molecules were adsorbed on its surface [34]. Therefore, the number of dye molecules adsorbed over the surface of $\mathrm{ZnO}$ catalyst is relatively more in comparison with number of reactive radicals available for attack. Hence, photodegradation decreases $[34,35]$. Also,the increased concentration of dye solution interrupts the photons before reaching to the $\mathrm{ZnO}$ surface which in terms decreases the absorption of photons and consequently reduces the photodegradation of dye [34]. Hence $100 \mathrm{ml}$ $50 \mathrm{ppm}$ Rose Bengal dye solution was completely degraded by $100 \mathrm{mg}$ of $\mathrm{ZnO}$ at $\mathrm{pH} 8$ on 4 hours of illumination under the aforesaid light source.

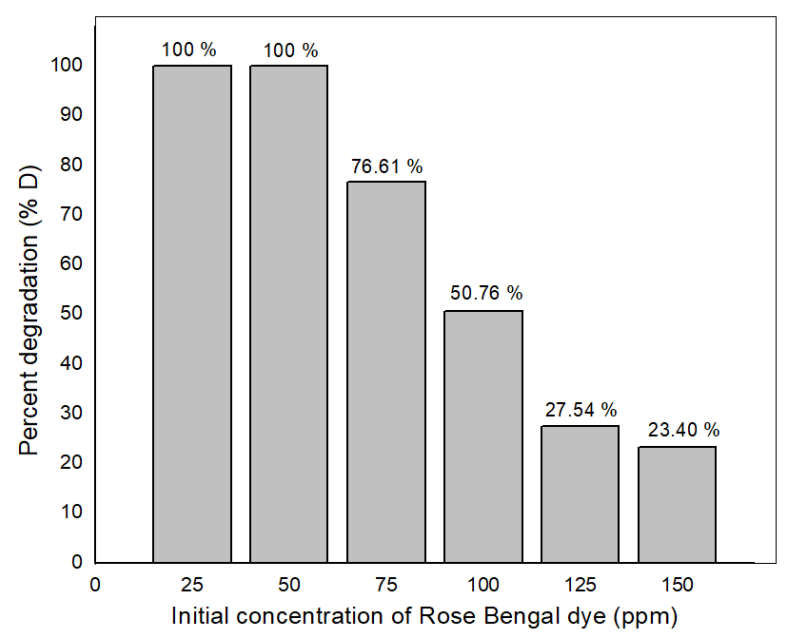

FIG. 10. Variation of percent (\%) degradation of Rose Bengal dye over $\mathrm{ZnO}$ with initial dye concentration

3.2.5. Effect of the irradiation time. The PCD of $75 \mathrm{ppm}$ Rose Bengal dye under the optimum conditions (Catalytic loading $100 \mathrm{mg} \mathrm{ZnO/} 100 \mathrm{ml}$ of dye solution at $\mathrm{pH} 8$ ) in artificial light was found to increase with increase in irradiation time and within 8 hours there was $100 \%$ degradation (Fig. 11). When 75 ppm Rose Bengal dye solution along with $\mathrm{ZnO}$ is magnetically stirred for 8 hours in the absence of light (dark), negligible $(6-7 \%)$ photodegradation was observed. For reference it is considered as zero hour irradiation. It is observed that with increase in irradiation time, the absorbance of Rose Bengal dye decreases and after $8 \mathrm{~h}$ irradiation of sunlight it becomes zero. 


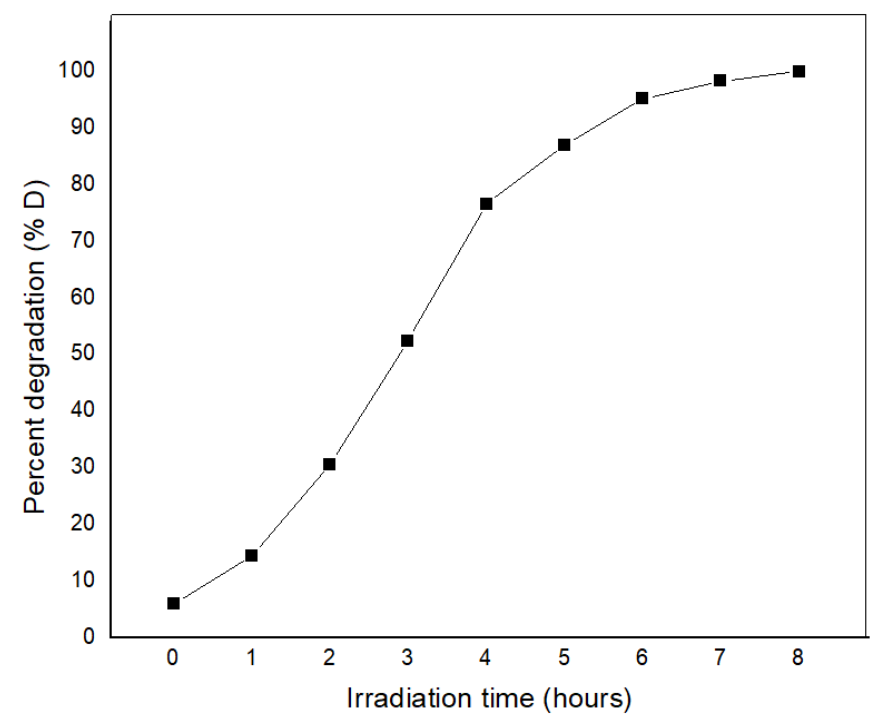

FIG. 11. Variation of percent (\%) degradation of Rose Bengal dye over $\mathrm{ZnO}$ with irradiation time

3.2.6. Reusability of $\mathrm{ZnO}$ catalyst. The stability of $\mathrm{ZnO}$ nanoparticle catalyst was also studied. The $\mathrm{ZnO}$ materials were recovered from reaction mixture by centrifugation followed by filtration and were reused for 3 times under identical experimental conditions. It is found that even reused $\mathrm{ZnO}$ nanoparticles were efficient for the degradation of Rose Bengal and there was negligible change in its photocatalytic activity.

\section{Conclusion}

In the present research work,

1. Zinc Oxide $(\mathrm{ZnO})$ was successfully synthesized by an efficient mechanochemical method via zinc oxalate dihydrate precursor.

2. Photocatalytic operational parameters for the Rose Bengal dye degradation over $\mathrm{ZnO}$ under artificial light illumination were satisfactorily studied and optimized.

3. $\mathrm{ZnO}$ was found to be an efficient photocatalyst for degradation of Rose Bengal dye.

4. In dark conditions, $\mathrm{ZnO}$ is found to be inactive.

5. Rose Bengal solutions of lower concentration were completely mineralized by photo-degradation on the surface of $\mathrm{ZnO}$.

\section{Acknowledgements}

Authors specifically wish to thank PDEA's Annasaheb Waghire College, Otur and Baburaoji Gholap College, Sangvi for offering their continuous and valuable support, in terms of facilities like laboratories for all experimental work, instrumental facilities for the characterization of materials and libraries for the literature review.

\section{References}

[1] Mancosu N., Snyder R.L., Kyriakakis G., Spano D. Water Scarcity and Future Challenges for Food Production. Water, 2015 , 7, P. 975-992.

[2] Ding, Y., Hayes M.J., Widhalm M. Measuring economic impacts of drought: a review and discussion. Disaster Prevention and Management, 2011, 20 (4), P. 434-446.

[3] Van Leeuwen C.C.E., Cammeraat E.L.H., de Vente J., Boix-Fayos C. The evolution of soil conservation policies targeting land abandonment and soil erosion in Spain: A review. Land use policy, 2019, 83, P. 174-186.

[4] Velayatzadeh M. Introducing the causes, origins and effects of dust in Iran. J. of Air Pollution and Health, 2020, 5 (1), P. 63-70.

[5] He B., Cui X., Wang H., Chen A. Drought: The most important physical stress of terrestrial ecosystems. Acta Ecologica Sinica, 2014, 34 (4), P. 179-183.

[6] Humphries P., Baldwin D.S. Drought and aquatic ecosystems: an introduction. Freshwater biology, 2003,48 (7), P. $1141-1146$.

[7] Bifulco M., Ranieri R. Impact of drought on human health. European J. of internal medicine, 2017, 46, e9-e10.

[8] Bellemare M.F. Rising food prices, food price volatility, and social unrest. American J. of agricultural economics, 2015,97 (1), P. 1-21.

[9] Ibelings Bas W., Chorus I. Accumulation of cyanobacterial toxins in freshwater "seafood" and its consequences for public health: a review. Environmental pollution, 2007, 150 (1), P. 177-192.

[10] Braun A., Augustynski J., et. al. Photocatalysis for energy and environmental sustainability. J. Mater. Res., 2010,25 (1), P. 1-2.

[11] Legrini O., Oliveros E., Braun A.M. Photochemical processes for water treatment. Chemical reviews, 1993, 93 (2), P. 671-698. 
[12] Barka N., Qourzal S., Assabbane A., Ait-Ichou Y. Solar photocatalytic degradation of textile dyes on dynamic pilot plant using supported $\mathrm{TiO}_{2}$. Arabian J. for Science and Engineering, 2010, 35 (2A), 131.

[13] Parsons S., ed. Advanced oxidation processes for water and wastewater treatment, IWA publishing, 2004.

[14] Munoz I., Rieradevall J., et al. Environmental assessment of different solar driven advanced oxidation processes. Solar Energy, 2005, 79 (4), P. 369-375.

[15] Yu Z., H. Keppner, et al. Photocatalytic discoloration of Methyl Orange on innovative parylene-TiO 2 flexible thin films under simulated sunlight. Applied Catalysis B: Environmental, 2008, 79 (1), P. 63-71.

[16] Chan, Samuel Hong Shen, et al. Recent developments of metal oxide semiconductors as photocatalysts in advanced oxidation processes (AOPs) for treatment of dye waste-water. J. of Chemical Technology \& Biotechnology, 2011, 86 (9), P. 1130-1158.

[17] Mills A., Davies R.H., Worsley D. Water purification by semiconductor photocatalysis. Chemical Society Reviews, 1993, 22 (6), P. 417-425.

[18] Rajeshwar K., Osugi M.E., et al. Heterogeneous photocatalytic treatment of organic dyes in air and aqueous media. J. of photochemistry and photobiology C: photochemistry reviews, 2008, 9 (4), P. 171-192.

[19] Vidya C., Chandra Prabha M.N., Antony Raj M.A.L. Green mediated synthesis of zinc oxide nanoparticles for the photocatalytic degradation of Rose Bengal dye. Environmental Nanotechnology, Monitoring \& Management, 2016, 6, P. 134-138.

[20] Mills A., Le Hunte S. An overview of semiconductor photocatalysis. J. of photochemistry and photobiology A: Chemistry, 1997, 108 (1), P. $1-35$.

[21] Drumond Chequer, Farah M., et al. Genotoxic and mutagenic effects of erythrosine B, a xanthene food dye, on HepG2 cells. Food and chemical toxicology, 2012, 50 (10), 3447.

[22] Zhang Huanqiu, Jun Peng, et al. Hybrid microtubes of polyoxometalate and fluorescence dye with tunable photoluminescence. Chemical communications, 2012, 48 (37), P. 4462-4464.

[23] Seo, Hyung-Kee, and Hyung-Shik Shin. "Study on photocatalytic activity of ZnO nanodisks for the degradation of Rhodamine B dye." Materials Letters 159 (2015): P. 265-268.

[24] Mpountoukas P., Pantazaki A., et al. Cytogenetic evaluation and DNA interaction studies of the food colorants amaranth, erythrosine and tartrazine. Food and Chemical Toxicology, 2010, 48 (10), P. 2934-2944.

[25] Ritchie E.E., Princz J.I., Robidoux P.J., Scroggins R.P. Ecotoxicity of xanthene dyes and a non-chlorinated bisphenol in soil. Chemosphere, 2013, 90 (7), P. 2129-2135.

[26] Pardeshi S.K., Patil A.B. Effect of morphology and crystallite size on solar photocatalytic activity of zinc oxide synthesized by solution free mechanochemical method. J. of Molecular Catalysis A: Chemical, 2009, 308 (1-2), P. 32-40.

[27] Wu L., Yu J.C., Fu X. Characterization and photocatalytic mechanism of nanosized CdS coupled $\mathrm{TiO}_{2}$ nanocrystals under visible light irradiation. J. of Molecular Catalysis A: Chemical, 2006, 244 (1-2), P. 25-32.

[28] JCPDS Card No. 36-1451.

[29] Nafees M., Liaqut W., Ali S., Shafique M.A. Synthesis of ZnO/Al: ZnO nanomaterial: structural and band gap variation in ZnO nanomaterial by Al doping. Applied Nanoscience, 2013, 3 (1), P. 49-55.

[30] Aparna P.U., Divya N.K., Pradyumnan P.P. Structural and dielectric studies of Gd doped ZnO nanocrystals at room temperature. J. of Materials Science and Chemical Engineering, 2016, 4 (2), P. 79-88.

[31] Behnajady M.A., Modirshahla N., Hamzavi R. Kinetic study on photocatalytic degradation of CI Acid Yellow 23 by ZnO photocatalyst. J. of hazardous materials, 2006, 133 (1-3), P. 226-232.

[32] Xia Juan, Anqi Wang, Xiang Liu, Zhongxing Su. Preparation and characterization of bifunctional, $\mathrm{Fe}_{3} \mathrm{O}_{4} / \mathrm{ZnO}$ nanocomposites and their use as photocatalysts. Applied Surface Science, 2011, 257 (23), P. 9724-9732.

[33] Anandan S., Vinu A., et al. Photocatalytic activity of $\mathrm{ZnO}$ impregnated $\mathrm{H} \beta$ and mechanical mix of $\mathrm{ZnO} / \mathrm{H} \beta$ in the degradation of monocrotophos in aqueous solution. J. of Molecular Catalysis A: Chemical, 2006, 256 (1-2), P. 312-320.

[34] Pardeshi S.K., Patil A.B. Solar photocatalytic degradation of resorcinol a model endocrine disrupter in water using zinc oxide. J. of hazardous materials, 2009, 163 (1), P. 403-409.

[35] Kaur Japinder, Sonal Singhal. Heterogeneous photocatalytic degradation of rose bengal: effect of operational parameters. Physica B: Condensed Matter, 2014, 450, P. 49-53. 